\title{
RANCANG BANGUN BOILER DAN TANGKI PENGUAPAN MINYAK ATSIRI PADA MESIN DESTILATOR DENGAN METODE UAP BERBAHAN BAKU DAUN SERAI (CYMBOPOGON NARDUS)
}

\author{
Muhammad Luthfi \\ Fakultas Teknik, Program Studi Teknik Mesin \\ Universitas Muria Kudus \\ Email : muhammadluthfi.pro@gmail.com \\ Rochmad Winarso \\ Fakultas Teknik, Program Studi Teknik Mesin \\ Universitas Muria Kudus \\ Email : Rochmad.Winarso@umk.ac.id \\ Rianto Wibowo \\ Fakultas Teknik, Program Studi Teknik Mesin \\ Universitas Muria Kudus \\ Email : rianto.wibowo@umk.ac.id
}

\begin{abstract}
ABSTRAK
Serai Wangi (Cymbopogon nardus) adalah salah satu tanaman rempah, biasa digunakan sebagai bumbu masakan, dan obat-obatan. Minyak atsiri dari serai dapat dihasilkan dengan berbagai metode misalnya ekstraksi. Keuntungan dari metode ini adalah tidak membutuhkan suhu yang tinggi, sehingga minyak tidak akan mudah rusak. Oleh karena itu dibuatlah boiler dan tangki bahan yang efektif dan memiliki inovasi yang dapat menghasilkan minyak atsiri yang dengan hasil rendemen yang bagus. Metode dalam perancangan dan pembuatan mesin destilator diawali dengan proses observasi di lapangan, buku, jurnal-jurnal yang berhubungan pembuatan boiler sebagai alat untuk memanaskan air dan tangki bahan sebagai wadah bahan daun serai. Konsep yang dilakukan perhitungan perancangan dan gambar desain menggunakan software inventor dan pembuatan, dan pengujian dalam penggunaan alat boiler dan tangki bahan.Hasil dari rancang bangun boiler dan tangki penguapan adalah proses penguapan dari boiler menuju tangki bahan berjalan dengan baik dan prosesnya yang efisien dapat menghasilkan minyak atsiri dengan kualitas dan kuantitas yang banyak.
\end{abstract}

Kata kunci: Serai, minyak atsiri, boiler, tangki penguapan.

\section{ABSTRACT}

Fragrant lemongrass (Cymbopogon nardus) is one of the herbs, commonly used as a cooking spice, and medicines. The essential oil of lemongrass can be produced by various methods such as extraction. The advantage of this method is not to require high temperatures, so the oil will not be easily damaged. Therefore, an effective and innovative boiler and tank of ingredients that can produce essential oils with good yields are produced. The method of design and manufacture of destilator machine begins with field observation process, books, journals related boiler making as a tool for heating water and tank material as a container of lemongrass leaf material. The concept of design calculation and drawing design using inventor and manufacture software, and testing in the use of boiler and tank materials. The expected results for the design of boiler and material tank is the evaporation process from the boiler to the material tank will run well and efficient process can produce volatile oil with the quality and quantity that much.

Keywords: Lemongrass, essential oil, boiler, material tank. 


\section{PENDAHULUAN}

Perkembangan zaman dan di era digital sekarang ini, banyak orang-orang di dunia ini yang menginginkan hasil secara instan. Di dalam dunia permesinan dan teknologi, evolusi tersebut selalu berubah-ubah seiring perkembangan zaman.

Mesin destilator dengan menggunakan metode uap merupakan cara yang lebih cepat untuk menghasilkan minyak atsiri yang optimal. Sebagai bahan baku utama, serai merupakan jenis tumbuhan rumput-rumputan yang dimanfaatkan sebagai bumbu dapur untuk mengharumkan makanan.

Minyak serai wangi yang berasal dari Cymbopogon nardus sering digunakan sebagai pewangi, disamping itu minyak ini memiliki beberapa khasiat diantaranya sebagai anti bakteri, anti jamur dan mencegah atheromatosis. Salah satu produksi minyak serai wangi yaitu dapat dilakukan dengan metode destilasi. Berdasarkan hasil penelitian, menunjukan rendemen minyak serai wangi tertinggi dihasilkan pada metode destilasi uap sebesar 1,4\%. Sedangkan hasil GC-MS menunjukan komponen minyak atsiri paling banyak diperoleh pada minyak serai wangi hasil destilasi uap dan air-uap yaitu sebanyak 41 komponen. [4] susunan kimia minyak serai wangi di ytunjukkan pada tabel 1 .

Tabel 1. Susunan kimia minyak serai wangi $[1]$

\begin{tabular}{lc}
\hline \multicolumn{1}{c}{ Senyawa Penyusun } & Kadar (\%) \\
\hline Sitronellal & $32-45$ \\
Geraniol & $12-18$ \\
Sitronellol & $12-15$ \\
Geraniol Asetat & $3-8$ \\
Sitronellil Asetat & $2-4$ \\
L-Limonene & $2-5$ \\
Elenol dan Seskwiterpene lain & $2-5$ \\
Elemen dan Cadinene & $2-5$ \\
\hline
\end{tabular}

Kebanyakan tanaman serai wangi digunakan sebagai bumbu masakan, pembangkit cita rasa pada minuman dan obat-obatan herbal. Selain itu serai wangi juga digunakan sebagai bahan campuran dalam saus, sambal goring,sambal petis dan saus ikan. Sedangkan pada industri pangan, minyak serai wangi digunakan pada daging, permen, dan lain-lainnya. Berkembangnya zaman, tanaman serai wangi banyak digunakan sebagai bahan utama pewangi pada detergen, sabun, dan lotion. [5]

Minyak atsiri mulai banyak dimanfaatkan oleh manusia, mulai dari pemanfaatan bau dari minyak atsiri sampai penggunaan minyak atsiri sebagai bahan obat - obatan dan juga sebagai bahan aditif makanan. Minyak atsiri memiliki karakteristik pada fisiknya berupa cairan yang kental yang dapat disimpan pada sushu ruang yaitu sekitar $20-25$ derajat celcius.Bahan baku pada minyak atsiri berbagai macam tumbuhan seperti buah, bunga, daun, biji, kulit biji, batang, akar, atau rimpang. Ciri - ciri minyak atsiri yaitu beraroma khas pada baunya dan memiliki sifat mudah menguap. [1]

Dengan adanya penelitian tentang destilator minyak atsiri ini, diharapkan kedepannya adanya produksi missal menggunakan kreasi dan inovasi yang lebih modern.

\section{METODOLOGI PENELITIAN}

Metodologi penelitian ini di mulai dari observasi lapangan dan studi literatur, menganalisa kebutuhan serta membuat konsep, selanjutnya melakukan perancangan dan perhitungan. Metode yang digunakan di perlihatkan pada gambar 1 diagram alir dibawah: 


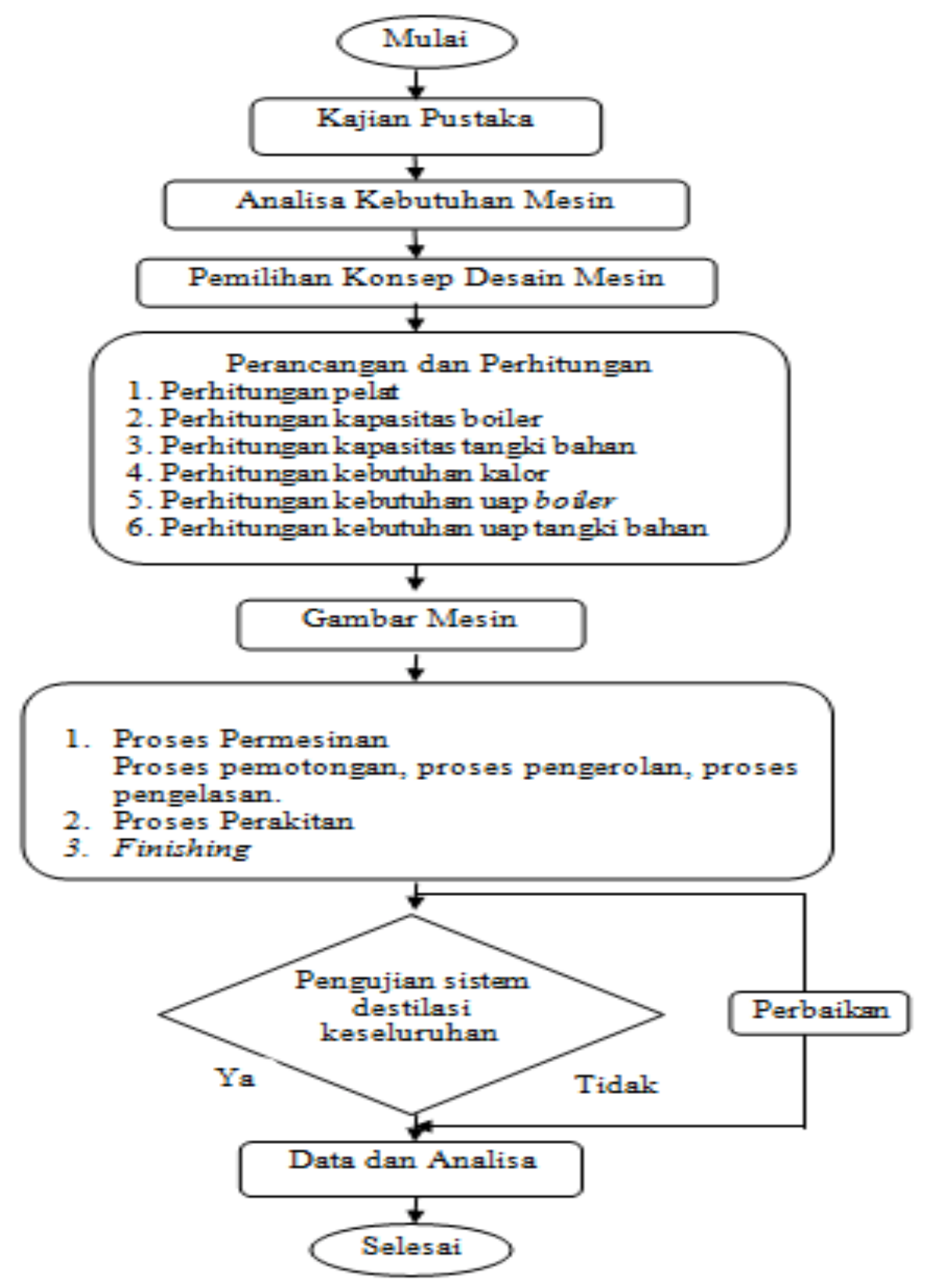

Gambar 1. Diagram alir

Dari beberapa aspek pemilihan konsep yang mengacu pada penelitian sebelumnya dapat disimpulkan bahwa pemilihan konsep desain yang paling efisien adalah konsep dengan gambar 2 sebagai berikut: 


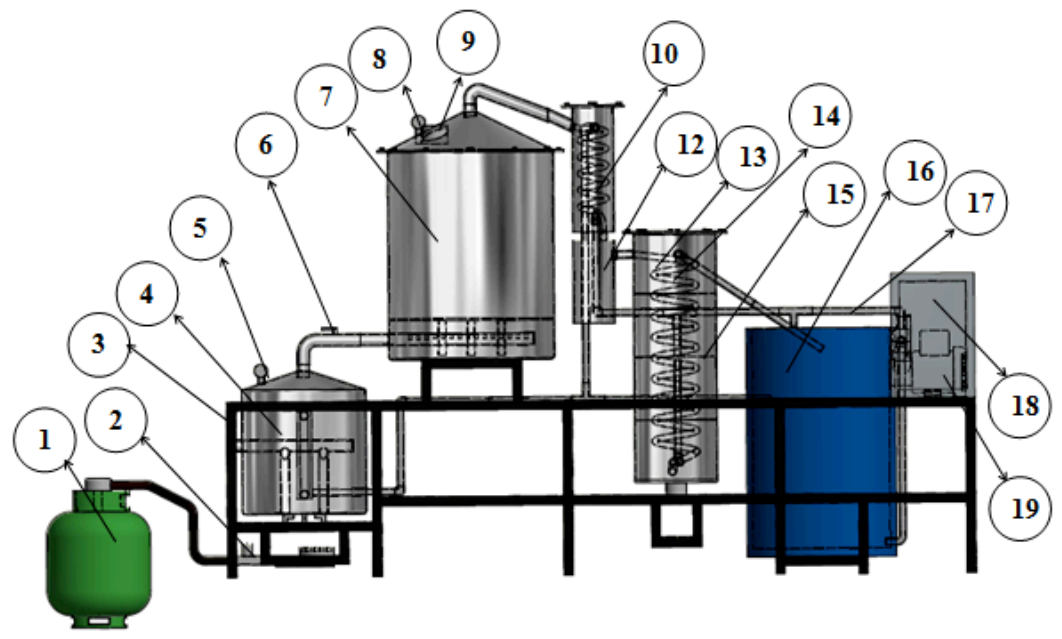

Gambar 2. Destilator

Keterangan :
1. Tabung gas
2. Pengontrol api
3. Rangka mesin
4. Tangki boiler
5. Pressure gauge
6. Stop kran
7. Tangki penguapan
8. Pressure gauge
9. Manometer gauge
10. Kondensor 1

\author{
11. Pipa tembaga \\ 12. Tabung penampung embun air \\ 13. Kondensor 2 \\ 14. Pipa tembaga \\ 15. Pelat sirip kondensor 2 \\ 16. Bak air pendingin \\ 17. Saluran air pendingin \\ 18. Box kontrol mesin \\ 19. Pompa air
}

Prinsip kerja dari perancangan distilator tipe uap adalah sebagai berikut :

1. Air dari tangki penampung air pendingin akan di pompa menuju tangki boiler.

2. Tangki boiler akan terus di panaskan hingga air akan menguap menuju ke tangki penguapan oleh pipa penyalur uap.

3. Uap air yang berada di dalam tangki penguapan akan menguapkan bahan baku hingga senyawa minyak atsiri ikut menguap bersamaan dengan uap air menuju ke kondensor 1 .

4. Di dalam kondensor 1 uap hasil penyulingan akan di dinginkan melalui pipa tembaga spiral yang luarnya di aliri air seacara terus menerus dengan temperatur pengembunan air untuk mengurangi kadar air dari hasil penyulingan yang di tampung pada wadah penampung menuju ke kondensor 2.

5. Di dalam kondensor 2 uap hasil penyulingan akan di dinginkan untuk mendapatkan hasil minyak atsiri melalui pipa tembaga spiral yang di luarnya dialiri air secara terus menerus sehingga senyawa dari fase uap akan menjadi fase cair menuju wadah penampung hasil minyak.

6. Didalam wadah penampung menghasilkan minyak atsiri serai wangi dari proses mesin destilasi. 


\section{HASIL DAN PEMBAHASAN}

\subsection{Boiler}

Boiler sebagai tempat untuk memanaskan air, dimana boiler ini memiliki efisiensi dibanding tangki pemanas biasa karena di dalam boiler terdapat pipa api yang berfungsi sebagai penyalur energi panas agar lebih cepat mengubah air menjadi uap. Berikut gambar 3 boiler:

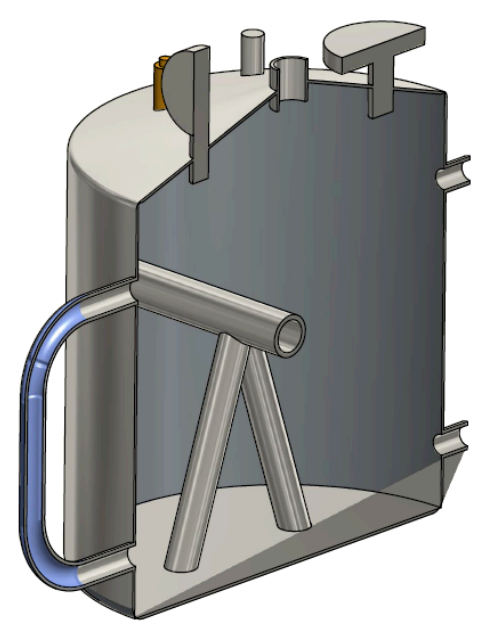

Gambar 3. Boiler

Perhitungan dalam perancangan boiler adalah perhitungan untuk mencari tebal tangki boiler, tebal pipa api, tubesheet, ligament, kebutuhan kalor, kebutuhan bahan bakar, kapasitas uap didasarkan pada beberapa rumus sebagai berikut: Perhitungan ketebalan pelat tangki boiler berdasarkan rumus 1 :

$t=\frac{P R}{S E-0.6 P}$

Tebal pada ttangki boiler sangat penting bagi perancangan karena dengan tekanan perancangaan 3 bar berapa ketebalan minimal yang dapat digunakan sebagai acuan pembuatan boiler. Perhitungan ketebalan pelat pipa api berdasarkan rumus 2 :

$t=\frac{P R}{S E-0.6 P}+0.04$

Ketebalan pipa api dibutuhkan untuk mencari tebal yang tahan akan tekanan terhadap api dan tekanan dari dalam sebesar 3 bar. Perhitungan kapasitas keseluruhan berdasarkan rumus 3 :

$v=\pi r^{2} t$

Kapasitas keseluruhan dari tangki boiler dengan tinggi dan diameter yang sudah ditentukan 300 mm x $300 \mathrm{~mm}$. Perhitungan tubesheet berdasarkan rumus 4 dan 5 : 
$t=\sqrt{\left(\frac{P}{C S}\right)}\left(\frac{p^{2}-\pi D^{2}}{4}\right)$

Tubesheet merupakan landasan untuk menopang pipa api, maka dicari ketebalan yang sanggup menahan tekanan 3 bar.

$$
p=\frac{C S t^{2}}{p^{2}-\left(\frac{\pi D^{2}}{4}\right)}
$$

Dengan ketebalan minimal yang sudah ditentukan, maka dengan mencari (p), maka didapatkan tekanan yang didapat pada tubesheet. Perhitungan ligament berdasarkan rumus 6 :

$$
E=\frac{p-d}{p}
$$

Ligament merupakan jarak antar lubang pipa api pada tubesheet. Dicari efisiensi ligament untuk menghasilkan kualitas yang baik dalam proses pengapian. Volume badan boiler berdasarkan rumus 7 :

$$
V_{\text {Badan boiler }}=\operatorname{Lb} \times t_{b a}
$$

Volume badan boiler adalah bagian utama dimana tempat air berada. Dengan luas alas dikalikan dengan tinggi air pengisian terhadap badan boiler maka menghasilkan volume tersebut. Perhitungan volume pipa api berdasarkan rumus 8 dan 9 :

VPipa api $=$ Lt $x t_{\text {ta }}$

Dengan menggunakan luas alas pipa api dikalikan tinggi pipa api menghasilkan volume pipa api.

$V_{\text {Pipa api }}($ total $)=V t \times$ jumlah pipa api

Total volume pipa api dengan jumlah pipa api sebanyak 4 akan menghasilkan volume total. Perhitungan volume air berdasarkan rumus 10 :

$V_{\text {air }}=V_{\text {Badan }}$ boiler $-V_{\text {pipa api }}($ total $)$

Untuk mendapatkan volume air, maka menggunakan volume badan boiler dikurangi dengan volume pipa api total. Perhitungan jumlah kalor masuk pada boiler berdasarkan rumus 11 :

$Q_{1}=S \times \Delta i$

Untuk mendapatkan jumlah kalor yang masuk pada boiler maka S (kapasitas air) boiler dikalikan dengan $\Delta \mathrm{i}$. Perhitungan kebutuhan bahan bakar berdasarkan rumus 12 : 


$$
B=\frac{Q_{1}}{L H V \times \eta_{\text {boiler }}}
$$

Kebutuhan bahan bakar yang dibutuhkan per jam nya, LHV merupakan nilai kalor bawah sedangkan $(\eta)$ adalah efisiensi boiler. Perhitungan jumlah kalor untuk mengubah air menjadi uap berdasarkan rumus 13 :

$Q_{2}=M x \operatorname{cp} x \Delta t$

Jumlah kalor yang dibutuhkan untuk mengubah air dari temperature $27^{\circ} \mathrm{C}$ menjadi $100^{\circ} \mathrm{C}$. Perhitungan kebutuhan uap berdasarkan rumus 14 dan 15 :

$$
M_{\text {air }}=M_{\text {uap }}
$$

Massa air yang ada pada tangki boiler akan menghasilkan massa uap yang sama dengan asumsi massa air habis sehingga uap yang dihasilkan sebanding.

$K=\frac{\eta x G_{b b} x N . O}{\Delta \text { Enthalpi }}$

Kapasitas uap adalah massa uap yang dihasilkan perjamnya dari massa air keseluruhan yang ada pada boiler.

Perhitungan dalam perancangan boiler didasarkan pada beberapa rumus sebagaimana pada rumus 1-15 dengan hasil pada tabel 2 sebagai berikut:

Tabel 2. Hasil perhitungan boiler

\begin{tabular}{lc}
\hline \multicolumn{1}{c}{ Perhitungan } & Hasil \\
\hline Ketebalan minimal pelat tangki boiler & $0,48 \mathrm{~mm}$ \\
Ketebalan minimal pipa api & $0,07 \mathrm{~mm}$ \\
Kapasitas keseluruhan tangki boiler & $21195000 \mathrm{~mm}^{3}$ \\
Ketebalan minimal tubesheet & $0,27 \mathrm{~mm}$ \\
Tekanan tubesheet & $35,2 \mathrm{lb} / \mathrm{in}^{2}$ \\
Efisiensi ligament & $75 \%$ \\
Volume badan boiler & $10597500 \mathrm{~mm}^{3}$ \\
Volume pipa api & $34029 \mathrm{~mm}^{3}$ \\
Volume pipa api total & $136116 \mathrm{~mm}^{3}$ \\
Kalor masuk pada boiler & $23597,13 \mathrm{~kJ} / \mathrm{jam}$ \\
Kebutuhan bahan bakar & $0,5 \mathrm{~kg} / \mathrm{jam}$ \\
Kalor mengubah air menjadi uap & $3066000 \mathrm{Joule}$ \\
Kapasitas uap & $4,5 \mathrm{~kg} / \mathrm{jam}$ \\
\hline
\end{tabular}

\subsection{Tangki Penguapan}

Tangki penguapan merupakan tempat bahan yang akan disuling, di mana bahan dapat berhubungan langsung dengan air atau dengan uap. Tangki penguapan umumnya berbentuk silinder dan terbuat dari seng tebal (galvanized sheet metal), dilengkapi dengan penutup yang dapat ditutup rapat. Prinsip kerja penyulingan dengan uap langsung adalah bahan baku diletakkan di atas saringan di dalam ketel dan dialirkan uap dari tempat yang berbeda (dari boiler). [2] 
Konstruksi tangki penguapan dengan metode uap langsung memiliki kapasitas yang lebih besar dibandingkan dengan tangki penguapan pada metode kukus. Perbandingan diameter tangki penguapan pada metode uap langsung dengan tingginya sebaiknya $1: 1,5$. [3]

Tangki penguapan yang dirancang mempunyai flange sebagai tempat untuk pemasangan ulir dan mur. Desain tangki penguapan terdapat pada gambar 4 berikut :

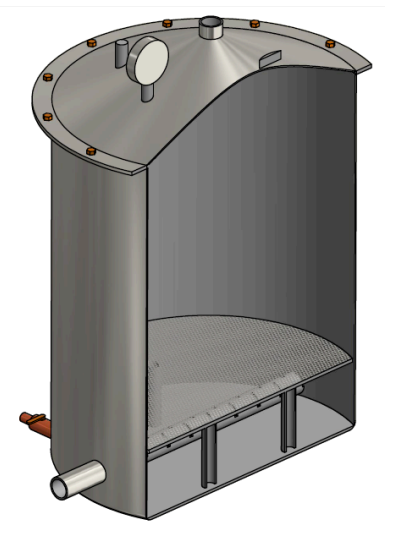

Gambar 4. Tangki penguapan

Perhitungan dalam perancangan tangki penguapan adalah perhitungan untuk mencari tebal tangki dan kapasitas tangki didasarkan pada beberapa rumus sebagai berikut: Perhitungan ketebalan pelat tangki penguapan berdasarkan rumus 16 :

$t=\frac{P R}{S E-0.6 P}$

Tebal pada tangki tangki penguapan sangat penting bagi perancangan karena dengan tekanan perancangaan 3 bar berapa ketebalan minimal yang dapat digunakan sebagai acuan pembuatan tangki penguapan. Perhitungan kapasitas keseluruhan tangki penguapan berdasarkan rumus 17 :

$v=\pi r^{2} t$

Kapasitas keseluruhan dari tangki penguapan dengan tinggi dan diameter yang sudah ditentukan $400 \mathrm{~mm}$ x $500 \mathrm{~mm}$.

Perhitungan dalam perancangan tangki penguapan didasarkan pada beberapa rumus sebagaimana pada rumus 16 - 17 dengan hasil pada tabel 3 sebagai berikut:

Tabel 3. Hasil perhitungan tangki penguapan

\begin{tabular}{ll}
\hline Perhitungan & Hasil \\
\hline Tebal pelat tangki penguapan & $0,508 \mathrm{~mm}$ \\
Kapasitas keseluruhan tangki penguapan & $62800000 \mathrm{~mm}^{3}$ \\
\hline
\end{tabular}

Berdasarkan proses perhitungan dalam perancangan telah dihasilkan penelitan perancangan boiler dan tangki penguapan dengan spesifikasi lengkap sebagai berikut:
a. Boiler
1. Material
: Pelat stainless steel 304 tebal $2 \mathrm{~mm}$.
2. Diameter
: $300 \mathrm{~mm}$
3. Tinggi
: $300 \mathrm{~mm}$ 
b. Tangki penguapan

1. Material

2. Diameter

: Pelat stainless steel 304 tebal $2 \mathrm{~mm}$.

3. Tinggi

: $400 \mathrm{~mm}$

: $500 \mathrm{~mm}$

\subsection{Simulasi Tekanan Boiler dan Tangki penguapan}

Bagian atau komponen mesin distilator yang terkena tekanan paling besar diantara bagian mesin distilator adalah tangki, diasumsikan tekanan dalam tangki 3 bar sesuai dengan safety valve maka dari itu dilakukan simulasi beban statis menggunakan software FEA (Finite Element Analysis) dengan material stainless steel 304. Mechanical properties material yang digunakan adalah sebagai tabel 4 berikut :

Tabel 4. Mechanical properties

\begin{tabular}{ll}
\hline Properties & Value \\
\hline Yield Strength & $206,843 \mathrm{MPa}$ \\
Tensile Strength & $482,633 \mathrm{MPa}$ \\
Elastic Modulus & $193,053 \mathrm{GPa}$ \\
Poisson Ratio & $0,29 \mathrm{ul}$ \\
Mass Density & $7,99949 \mathrm{~g} / \mathrm{cm}^{\wedge} 3$ \\
Shear Modulus & $7,99949 \mathrm{~g} / \mathrm{cm}^{\wedge} 3$ \\
Thermal Expansion Coefficient & $8,09 \mathrm{BTU} /(\mathrm{hr}-\mathrm{ft}-\mathrm{F})$ \\
\hline
\end{tabular}

Hasil keseluruhan simulasi menggunakan software FEA pada boiler ditunjukkan pada tabel 5 berikut :

Tabel 5. Hasil simulasi boiler

\begin{tabular}{lll}
\hline Name & Minimum & Maksimum \\
\hline Mass & $6,88422 \mathrm{~kg}$ & \\
Volume & $860582 \mathrm{~mm}^{\wedge} 3$ & \\
Von Mises Stress & $1,04954 \mathrm{MPa}$ & $134,687 \mathrm{MPa}$ \\
Displacement & $0,0000100368 \mathrm{~mm}$ & $0,196172 \mathrm{~mm}$ \\
Strain & $0,00000469225 \mathrm{ul}$ & $0,000619278 \mathrm{ul}$ \\
\hline
\end{tabular}

Hasil simulasi menggunakan software FEA pada boiler dengan format gambar agar lebih terperinci pada gambar 5 dibawah :
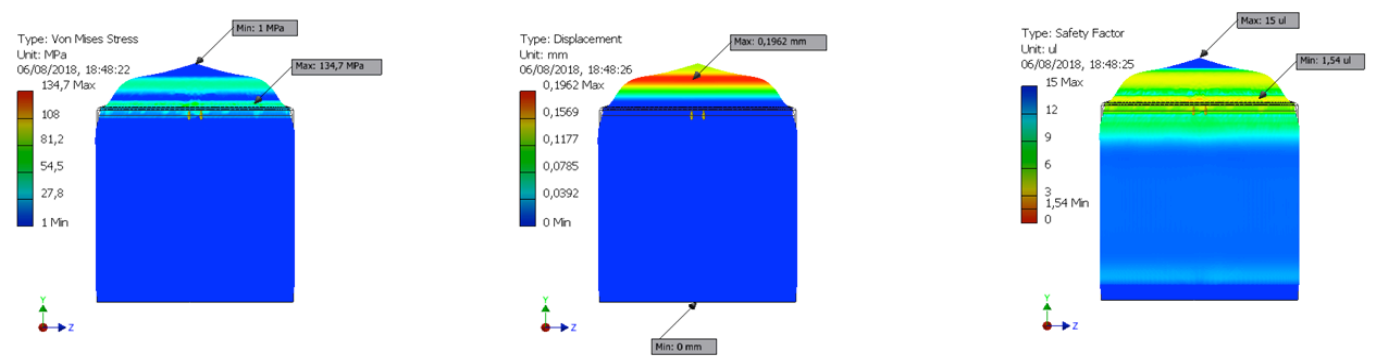

Gambar 5. Hasil simulasi boiler 
Hasil keseluruhan simulasi menggunakan software FEA pada tangki penguapan ditunjukkan pada tabel 6 berikut :

Tabel 6. Hasil simulasi tangki penguapan

\begin{tabular}{lll}
\hline Name & Minimum & Maksimum \\
\hline Mass & $32,4214 \mathrm{~kg}$ & \\
Volume & $0,00187987 \mathrm{~m}^{3}$ & \\
Von Mises Stress & $1,43509 \mathrm{MPa}$ & $1,43509 \mathrm{MPa}$ \\
Displacement & $0,00512027 \mathrm{~mm}$ & $0,196329 \mathrm{~mm}$ \\
Strain & $0,00000864525 \mathrm{ul}$ & $0,000486098 \mathrm{ul}$ \\
\hline
\end{tabular}

Hasil simulasi menggunakan software FEA pada tangki penguapan dengan format gambar agar lebih terperinci pada gambar 6 dibawah :

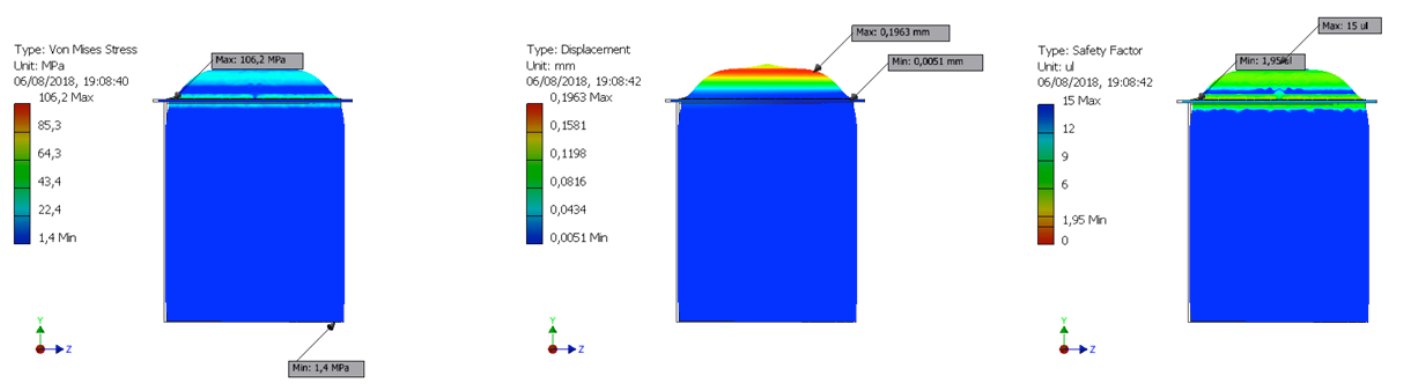

Gambar 6. Hasil simulasi tangki penguapan

\subsection{Hasil Pengujian}

Pengujian mesin destilator yang sudah dirancang dan dibuat penulis adalah bagian boiler dan tangki penguapan. Sasaran pengujian yang dilakukan adalah kinerja dari boiler dan tangki penguapan dan fungsi dari keduanya yang harus berjalan dengan semestinya.

Jadi setelah dilakukan pengujian mesin destilator, menghasilkan kesimpulan sebagai berikut :

1. Boiler tidak mengalami kebocoran dalam pengujian.

2. Tangki penguapan tidak mengalami kebocoran dalam pengujian.

3. Komponen-komponen pendukung yang telah dipasang, mulai dari pressure gauge, thermometer bimetal, safety valve, kran, dan water level dapat berfungsi dengan baik.

4. Pengujian dilakukan menggunakan $4 \mathrm{~kg}$ bahan baku daun serai di dalam tangki penguapan.

5. Pengujian dilakukan selama 2 jam-3 jam.

6. Boiler dapat mencapai temperatur $100^{\circ} \mathrm{C}$ tidak mengalami kebocoran dengan kondisi air yang mendidih dengan massa kapasitas 10 liter dan menghasilkan uap serta pengujian dilakukan 3 kali berturut dengan komponen yang sama. Tabel 7 pengujian boiler sebagai berikut :

Tabel 7. Hasil pengujian boiler

\begin{tabular}{|c|c|c|c|c|}
\hline No & Kapasitas Air (L) & $\begin{array}{l}\text { Temperatur } \\
\left({ }^{\circ} \mathrm{C}\right)\end{array}$ & $\begin{array}{l}\text { Durasi Pengujian } \\
\text { (menit) }\end{array}$ & Daya Tahan \\
\hline 1 & 10 & 80 & 180 & Tidak bocor \\
\hline 2 & 10 & 90 & 180 & Tidak bocor \\
\hline 3 & 10 & 100 & 180 & Tidak bocor \\
\hline
\end{tabular}

7. Tangki penguapan dapat mencapai temperatur $100^{\circ} \mathrm{C}$ tidak mengalami kebocoran dan pada temperatur $80^{\circ} \mathrm{C}, 90^{\circ} \mathrm{C}$, dan $100^{\circ} \mathrm{C}$ sudah bisa mengekstrak daun serai $4 \mathrm{~kg}$ menjadi uap dengan tekanan 1 bar yang selanjutnya diproses pada kondensor. Tabel 8 hasil pengujian tangki penguapan sebagai berikut : 
Tabel 8. Hasil pengujian tangki penguapan

\begin{tabular}{llllll}
\hline No & $\begin{array}{l}\text { Bahan Baku } \\
(\mathbf{k g})\end{array}$ & $\begin{array}{l}\text { Temperatur } \\
\text { Tangki } \\
\text { Penguapan }\left({ }^{\circ} \mathrm{C}\right)\end{array}$ & $\begin{array}{l}\text { Durasi } \\
\text { Pengujian } \\
\text { (menit) }\end{array}$ & $\begin{array}{l}\text { Waktu } \\
\text { (menit) }\end{array}$ & Daya Tahan \\
\hline 1 & 4 & 80 & 180 & 25 & Tidak bocor \\
2 & 4 & 9 & 180 & 37 & Tidak bocor \\
3 & 4 & 100 & 180 & 45 & Tidak bocor \\
\hline
\end{tabular}

8. Hasil pengujian keseluruhan mesin destilator, masing-masing dengan temperatur pada tangki penguapan $80^{\circ} \mathrm{C}, 90^{\circ} \mathrm{C}, 100^{\circ} \mathrm{C}$. Mendapatkan hasil kadar minyak atsiri dengan total sekitar $160 \mathrm{ml}$ minyak atsiri murni. Dan minyak atsiri dengan kadar campuran dengan air yang berwarna kuning hijau sampai kuning yang berbau wangi, tabel 9 pengujian keseluruhan mesin destilator sebagai berikut :

Tabel 9. Hasil pengujian mesin destilator

\begin{tabular}{llllll}
\hline No & $\begin{array}{l}\text { Bahan } \\
\text { Baku } \\
(\mathbf{k g})\end{array}$ & $\begin{array}{l}\text { Durasi } \\
\text { Pengujian } \\
\text { (menit) }\end{array}$ & $\begin{array}{l}\text { Temperatur } \\
\text { Tangki } \\
\text { Penguapan }\left({ }^{\mathbf{0}} \mathbf{C}\right)\end{array}$ & $\begin{array}{l}\text { Temperatur } \\
\text { Sensor }\left({ }^{\mathbf{0}} \mathbf{C}\right)\end{array}$ & $\begin{array}{l}\text { Hasil Minyak } \\
\text { Atsri (ml) }\end{array}$ \\
\hline 1 & 4 & 60 & 80 & 89.50 & 70 \\
22 & 4 & 60 & 90 & 89.75 & 59 \\
3 & 4 & 60 & 100 & 90.25 & 28 \\
\hline
\end{tabular}

\section{KESIMPULAN}

Dari perancangan dan perhitungan yang sudah dilakukan, dapat diambil beberapa kesimpulan sebagai berikut:

1. Desain boiler menggunakan pelat stainless steel 304 dengan diameter $300 \mathrm{~mm}$, tinggi 300 $\mathrm{mm}$, dan tebal $2 \mathrm{~mm}$.

2. Desain tangki penguapan menggunakan pelat stainless steel 304 dengan diameter $400 \mathrm{~mm}$, tinggi $500 \mathrm{~mm}$, dan tebal $2 \mathrm{~mm}$.

3. Perhitungan boiler dengan kapasitas keseluruhan 21 liter, dan massa air pada boiler sebanyak 10.46 liter, kebutuhan kalor yang pada boiler $23597.13 \mathrm{~kJ} / \mathrm{jam}$, kebutuhan kalor air menjadi uap $3066 \mathrm{~kJ}$, kebutuhan bahan bakar $0.5 \mathrm{~kg} / \mathrm{jam}$, massa uap yang dialirkan sebesar 4.5 $\mathrm{kg} / \mathrm{jam}$.

4. Perhitungan tangki penguapan dengan kapasitas keseluruhan 62 liter, dan kebutuhan uap 4.5 $\mathrm{kg} / \mathrm{jam}$.

5. Simulasi software Autodesk Inventor 2015, bagian yang dianalisa adalah boiler dan tangki penguapan. Dengan tiap bagian menggunakan tekanan 3 bar $(0.3 \mathrm{Mpa})$ maka hasilnya berikut:

a. Pada boiler menghasilkan displacement maksimum $0.19 \mathrm{~mm}$ dan von misses stress maksimum 134.6 Mpa.

b. Pada tangki menghasilkan displacement maksimum $0.19 \mathrm{~mm}$ dan von misses stress maksimum 106.2 Mpa. 


\section{DAFTAR PUSTAKA}

[1] [1] A. Anwar, Nugraha, A. Nasution, and R. Amaranti, "Teknologi penyulingan minyak sereh wangi skala kecil dan menengah di jawa barat," Teknoin, vol. 22, no. 9, pp. 664-672, 2016.

[2] D. Nilam and W. S. Sari, Penyulingan Minyak Atsiri Dari Nilam. Jawa Timur, 2012.

[3] P. P. Yuni Eko F, Patar Jonathan S., Mahfud, "Pengambilan Minyak Atsiri dari Daun dan Batang Serai Wangi (Cymbopogon Winterianus) Menggunakan Distilasi Uap dan Air dengan Pemanasan Microwave," J. Tek. POMITS, 2013.

[4] Tristhy Novilia Angesti, "Perbandingan rendemen dan komponen minyak atsiri sereh wangi (," no. 06, p. 3953, 1995.

[5] W. Bota, M. Martosupono, dan S. Ferdy Rondonuwu, K. Kunci, and M. Sereh Wangi, "POTENSI SENYAWA MINYAK SEREH WANGI (CITRONELLA OIL) DARI TUMBUHAN Cymbopogon nardus L. SEBAGAI AGEN ANTIBAKTERI,”Semin. Nas. Sains dan Teknol. Fak. Tek. Univ. Muhammadiyah Jakarta, no. November, pp. 1-8, 2015. 